\title{
Use of geoinformation systems for forecasting and recognizing crisis situations in agriculture
}

\author{
Ekaterina Podryadchikova ${ }^{1, *}$, Larisa Gileva $^{2}$, Aleksey Dubrovsky ${ }^{3}$, and Elena Lobanova ${ }^{4}$ \\ ${ }^{1}$ Industrial University of Tyumen, 38 Volodarsky Str., 625000 Tyumen, Russia \\ ${ }^{2}$ Omsk State Agrarian University named after P. A. Stolypin, 1 Institutskaya Square, 644008 Omsk, \\ Russia \\ ${ }^{3}$ Siberian State University of Geosystems and Technologies, 10 Plakhotny St., 630108 Novosibirsk, \\ Russia \\ ${ }^{4}$ Novosibirsk State University of Economics and Management, 56 Kamenskaya St., 630099 \\ Novosibirsk, Russia
}

\begin{abstract}
This article covers the necessity of use of geoinformation systems for forecasting and recognizing crisis situations in agriculture. The method of creation of thematic maps was offered as a tool by the authors of the article, three thematic maps were obtained for functional zoning by the indicators of: financial state of agricultural production, ecological state expressed in monetary equivalent and forecast of crisis states in agriculture. The given method was proved within the boundaries of the 121 village councils of the central part of Novosibirsk region for 64 agricultural companies of different forms of organization.
\end{abstract}

\section{Introduction}

The agricultural lands represent the strategic resource of any state and predetermine the food security of the population. The efficient management of agricultural production depends in many aspects on the level of awareness of the soil condition and properties, field configuration, location of infrastructure facilities and transport flows, as well as forecasting and recognizing crisis situations [1].

The development of scientific knowledge and practical experience in forecasting and recognizing crisis situations in the agricultural production is particularly relevant in the conditions of the COVID-19 pandemic due to the common restrictions imposed and, as a result, the disruption of supply chains and economic ties in the most countries of the world.

Most of the problems entailing the development of crisis situations in the agricultural production can be solved by the development and implementation of the modern production systems using geoinformation technologies. Currently, the Russian Federation is actively introducing information and communication technologies in the agricultural production, including the use of geoinformation systems. The "Smart Land Use", "Smart Field", "Smart Garden" projects developed on the basis of geoinformation systems as part of the action

\footnotetext{
*Corresponding author: podryadchikova_ed@mail.ru
} 
plan for the implementation of the national platform "Digital Agriculture" can be given as an example [2].

The main and distinctive feature of the use of geoinformation systems is the ability to use a variety of algorithms for spatial analysis and operational processing of large data arrays. One of the most common and well-known areas of using geoinformation technologies in the agricultural production is the processing of the Earth remote sensing data [3].

\section{Materials and Methods}

The main cartographic area of geoinformation support for forecasting and recognizing crisis situations in the agricultural production is the thematic digital mapping that results in creating accurate digital maps of terrain, soils, crop conditions, climate, etc. [4].

Another important area, that develops through geoinformation support, is logistics. At present, the priority factor in the agricultural production zoning has become an orientation towards favourable climatic conditions with the best convenient further transportation of products [5].

The most well-known area of geoinformation support is the cadastre and land management system, the purpose of which is to ensure rational land use, planning, control and protection of land, including land plots as real estate located on the territory of the Russian Federation [6]. To forecast and recognize crisis situations in the agricultural production, it is necessary to provide for crisis management measures, namely, to analyse the agricultural productivity at a certain interval, clarify and update crop insurance premiums, annually compile multifactor models of crop yields [7].

The authors of the article offered the geoinformation system structure and obtained thematic maps of the functional zoning of crisis situations in agriculture as a tool for forecasting and recognizing crisis situations in the agricultural production.

The main elements of the geoinformation support system for forecasting crisis situations in the agricultural production are given in Fig. 1. 


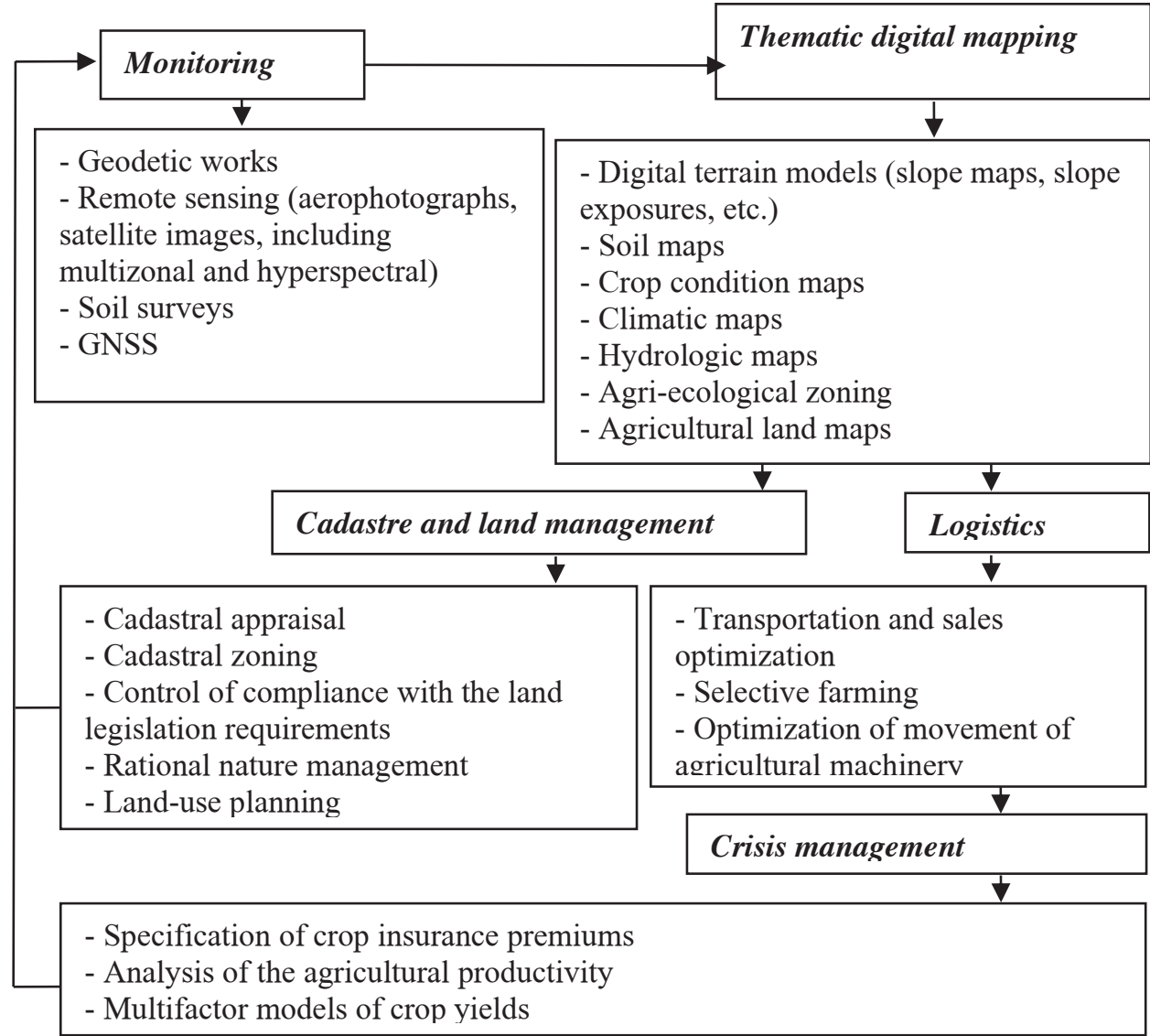

Fig. 1. Interaction of elements by using the geoinformation system for forecasting and recognizing crisis situations in agriculture

The method of creation of thematic maps for forecasting and recognizing crisis situations in the agricultural production can be represented as the work stages consequently performed: 1) to perform zoning of the territory according to the financial state indicator of the agricultural production; 2) to perform zoning of the territory according to the ecological state indicator expressed in the monetary equivalent; 3 ) to compare maps of financial and ecological states and consolidate them into an integral digital map of crisis states in agriculture.

At stage I, to perform zoning of the territory according to the financial state indicator of the agricultural production, for each minimum object of division of the territory, it is necessary to calculate the financial stability coefficient and the solvency coefficient according to the conventional formulas (1) and (2) of financial analysis.

$$
\mathrm{C}_{f s}=\frac{\left(C_{e c}+L_{l t}\right)}{P_{t o t}}
$$

where $\mathrm{C}_{f s}$ is the financial stability coefficient; $C_{e c}$ is the equity capital including all available reserves of the agricultural organization; Llt is long-term loans and credits (liabilities) with the period of involvement of more than 1 year; $P_{t o t}$ is the total amount of liabilities.

$$
C_{s}=\frac{C_{e c}}{\left(P_{1}+P_{2}+P_{3}\right)}
$$


where $\mathrm{C}_{\mathrm{s}}$ is the solvency coefficient; $C_{e c}$ is the equity capital including all available reserves of the agricultural organization; $P_{1}$ is the maturing liabilities, $P_{2}$ is the short-term liabilities, $P_{3}$ is the long-term liabilities.

The range scales of the financial stability and solvency coefficients by the groups of regions of the Russian Federation are given in Table 1.

Table 1. Values of financial stability and solvency coefficients

\begin{tabular}{|c|l|c|c|}
\hline $\begin{array}{c}\text { Group } \\
\text { No. }\end{array}$ & \multicolumn{1}{|c|}{ Description } & Cfs & Cs \\
\hline I & $\begin{array}{l}\text { The region where the organizations with absolute financial } \\
\text { stability and solvency are located. }\end{array}$ & $0.8-0.9$ & $0.5-0.7$ \\
\hline II & $\begin{array}{l}\text { The region where most of the organizations show financial } \\
\text { stability but insignificant lag in one of the criteria is allowed. }\end{array}$ & $0.7-0.9$ & $0.4-0.7$ \\
\hline III & $\begin{array}{l}\text { The agricultural organizations of the region are estimated as a } \\
\text { medium, since there are organizations with normal financial } \\
\text { stability but low solvency, and vice versa. }\end{array}$ & $0.6-0.7$ & $0.3-0.4$ \\
\hline IV & $\begin{array}{l}\text { The region with the organizations with financial non- } \\
\text { stability, the profit of such organizations is often lacking or } \\
\text { very insignificant but sufficient only for making mandatory } \\
\text { payments. }\end{array}$ & $0.4-0.6$ & $0.2-0.3$ \\
\hline V & $\begin{array}{l}\text { The region where most of the organizations are chronically } \\
\text { un-profitable, insolvent, with crisis financial state. }\end{array}$ & $\begin{array}{l}\text { less } \\
\text { than 0.4 }\end{array}$ & $\begin{array}{l}\text { less } \\
\text { than } 0.2\end{array}$ \\
\hline
\end{tabular}

At stage II, to perform zoning of the territory according to the ecological state indicator expressed in the monetary equivalent, it is necessary to calculate the costs for bringing the land plot to the maximum efficient state for use as an ecological component for each object of division of the territory according to the formula (3) presented in the article [8 ].

$$
\mathrm{ES}=\left(R_{a} \times P_{s}+N_{f} \times P_{f}+\mathrm{C}_{s t}\right) \times S+\frac{Y \times P \times P \times C \times \mathrm{S}}{\left(1+\frac{R}{100}\right)}+Z_{\text {tot }}
$$

ES is the ecological state indicator, $R_{a}$ is the recommended seed application rate, $\mathrm{t} / \mathrm{ha} ; P_{s}$ is the seed price, RUB/t; $P_{f}$ is the fertilisers price, RUB; $N_{f}$ is the recommended fertiliser application rate, $\mathrm{kg} / \mathrm{ha} ; C_{s t}$ is the soil treatment cost to be determined on the basis of crop cultivation technology, RUB/ha; $S$ is the land plot area, ha; $Y$ is the average crop yield for the production facility for the last 5 years, c/ha; $P$ is the price of a centner of products, RUB; $C$ is the correction factor considering the duration of restoration of fertility; $R$ is the refinancing rate of the Central Bank of Russia.

The values range scale is based on the percentage of costs for bringing the land plot to the maximum efficient state for use and current cadastral cost of the land plot by consolidated groups (Table 2).

Table 2. Value of the ecological state indicator

\begin{tabular}{|c|c|c|c|c|c|}
\hline Group No. & I & II & III & IV & V \\
\hline Description & $\begin{array}{c}\text { minimum } \\
\text { degree }\end{array}$ & average & significant & high & very high \\
\hline percentage & $0-20$ & $20-40$ & $40-60$ & $60-80$ & $80-100$ \\
\hline
\end{tabular}

At stage III with the use of the methods of spatial multifactor analysis, the obtained maps of the financial and ecological state are compared and consolidated into the integral digital map that can be used for forecasting and recognizing crisis situations in the agricultural production. To solve this task, the methods of spatial multifactor analysis, namely, geoprocessing and raster algebra, were used together with ArcGIS software product. 


\section{Results and Discussion}

The object of research is the agricultural land plots in the territory of Novisibirsk region that make $62.6 \%$ of total area of the region and occupy $11,128.5$ ths. ha. According to official statistics, the agricultural land plots in the territory of Novosibirsk region are mainly used as arable land for growing crops or as pastures for grazing, the rest of the agricultural land is the personal subsidiary farming and individual housing construction with household plots, vegetable gardens for growing vegetables and other crops.

The above method for creation of thematic maps for forecasting and recognizing crisis situations in the agricultural production was proved within the boundaries of the 121 village council territory of the central part of Novosibirsk region, including 64 agricultural companies of different forms of organization. The results are given in Table 3.

Table 3. Thematic maps for forecasting and recognizing crisis situations in the agricultural production

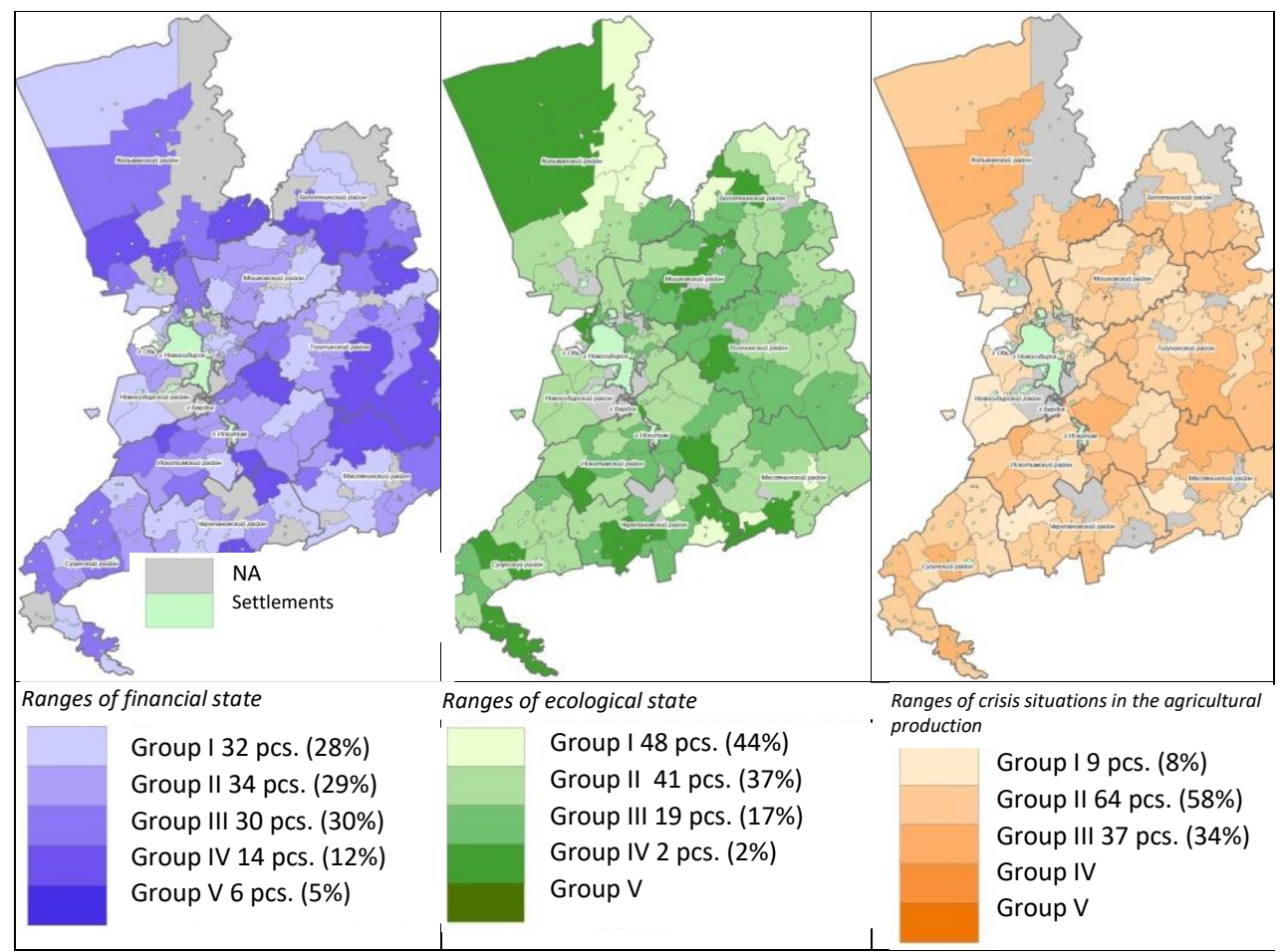

By analysing the thematic maps, it can be stated that the most part of the territory under review, namely that of 89 village councils, belongs to ecological state groups I and II, minimum and average need in restoration. The thematic map of the financial status shows that groups I, II and III include 96 village councils that are characterized by $28 \%, 29 \%$ and $30 \%$, respectively. It can be concluded from the consolidated thematic map of crisis situations there are no situations observed, ranges IV and V do not include the territory of any village council, and the main amount is within the ranges of groups II and III, 64 and 37 , respectively, that evidences rather stable state of the considered territory of Novosibirsk region. 


\section{Conclusions}

The article provides the method and results of thematic mapping for forecasting and recognizing crisis situations in agriculture. Such geoinformation support is an important component for agricultural management, control of rational land use, compliance with the land legislation requirements, and formation of logistics systems. To speed up the implementation of such digital innovative technologies, regular works on the detailed mapping of agricultural lands, soil content of agricultural lands, agri-ecological indicators should be performed with the use of the Earth remote sensing data.

\section{References}

1. J. A. Ingram, Food Sec., 3 (2011)

2. Departmental project «Digital Agriculture» - Federal state scientific institution «Rosinformagrotech», 48 (2019)

3. E. Tsoraeva, S. Mezhyan, M. Kataeva, L.Hugaeva, T.Rogova, GIS technologies used in zoning agricultural land for optimizing regional land use, E3S Web Conf. 224, 03001 (2020)

4. L.Klerkx, E. Jakku, P. Labarthe, Wageningen Journal of Life Sciences, 90 (2019)

5. O.A. Kosareva, M. N. Eliseev, V. P. Cheglov, A.N. Stolyarova, S. B. Aleksina, Eurasia J Biosci, 13 (2019)

6. V. V. Vershinin, T. N. Kovaleva, M. M. Demidova, P. P. Lebedev, Moscow Economic Journal, 5(1) (2018).

7. F. I. Ereshko, V. I. Medennikov, V. V. Kulba, Information society, 3 (2020)

8. E.D. Podryadchikova, L.N. Gilyova, Improvement of the methods of state cadastral assessment of agricultural lands while accounting the expenses for bringing a land plot to the state of maximum use efficiency, E3S Web Conf. 244, 03003 (2021) 